\title{
Peningkatan Kompetensi Siswa Melalui Pelatihan Teknologi Sepeda Motor
}

\author{
Hendra Dani Saputra ${ }^{1}$, Dedi Setiawan ${ }^{2}$, Dori Yuvenda ${ }^{3}$, Ahmad Arif $^{4}$, Rahmat Hidayat ${ }^{5}$ \\ ${ }^{1234}$ Jurusan Teknik Otomotif- Fakultas Teknik- Universitas Negeri Padang \\ ${ }^{5}$ Jurusan Teknik Elektro- Fakultas Teknik- Universitas Negeri Padang \\ *Author hendradani@ft.unp.ac.id
}

Revisi 05/06/2019;

Diterima 07/07/2019;

Publish 08/08/2019

Kata kunci:

Kompetensi,

Siswa,Pelatihan,

Teknolologi Sepeda

Motor

\begin{abstract}
Abstrak
Siswa-siswa SMK membutuhkan keahlian tentang teknologi sepeda motor terbaru, dimana kompetensi tersebut akan berguna oleh siswa ketika mereka menyeleseikan studinya di sekolah. Salah satu kompetensi teknologi sepeda motor terbaru yang diharapkan adalah kemampuan menggunakan dan menganalisis data hasil pemeriksaan alat pendeteksi kerusakan sepeda motor berupa Scan Tool. Kemampuan akhir yang diharapkan dari pelatihan ini, nantinya siswa mampu menggunakan dan menganalisis data hasil pemeriksaan serta melakukan perbaikan berdasarkan data dari Scan Tool. Program pelatihan bertujuan untuk mengembangkan dan meningkatkan kemampuan dari siswa kelas XII dalam menggunakan Scan Tool. Melalui program pelatihan ini diharapkan siswa mampu menggunakan, menganalisa dan melakukan perbaikan sepeda motor berdasarkan data dari Scan Tool. Sehingga siswa kelas XII memiliki kemampuan menggunakan dan menganalisa serta melakukan langkah perbaikan sepeda motor. Program pelatihan ini diberikan melalui metode pemberian modul teknologi sepeda motor , diskusi, menayangkan melalui slide tentang teknologi sepeda motor honda mesin serta mempraktekkan cara menggunakan dan menganalisis kerusakan sepeda motor. Sehingga diharapkan terjadi peningkatan kemampuan siswa kelas XII dalam kompetensi keahlian penggunaan dan analisa data kerusakan teknologi sepeda motor honda.
\end{abstract}

This is an open access article distributed under the Creative Commons Attribution License, which permits unrestricted use distribution, and reproduction in any medium, provided the original work is properly cited. (C2019 by author (s)

\section{PENDAHULUAN}

\section{Analisis Situasi}

Sejarah sistem bahan bakar sepeda motor di Indonesia dimulai dari era sistem bahan bakar menggunakan karburator. Selanjutnya dikembangkan sistem bahan bakar pada sepeda 


\section{Suluah Bendang: Jurnal Ilmiah Pengabdian Kepada Masyarakat}

Vol.19, No.3, 2019

Hendra Dani Saputra, Dedi Setiawan, dkk

motor menjadi sistem bahan bakar elektronik (Electronic Fuel Injection). Prinsip Sistem bahan bakar pada jenis karburator maupun jenis EFI adalah menghasilkan campuran bahan bakar dan udara pada komposisi yang tepat seusai dengan kondisi kerja mesin . Disamping itu sistem bahan bahan berguna sebagai sarana menjadikan komposisi campuran bahan bakar dan udara menjadi kabut bahan bakar yang sempurna. Dalam perkembangannya, teknologi sistem bahan bakar diharapkan mampu meningkatkan ketepatan komposisi campuran bahan bakar dan udara sesuai dengan kondisi kerja mesin sehingga proses pembakaran berlangsung lebih baik dan emisi gas buang yang dihasilkan menjadi lebih rendah. Salah satu solusi yang diberikan adalah melalui teknologi injeksi bahan bakar elektronik (Electronic Fuel Injection (EFI) System).

Ada dua jenis sistem EFI pada sepeda motor berdasarkan banyaknya titik injeksi, yakni : (1) single point injection (SPI) dan (2) multi point injection (MPI). Jenis single point fuel injection atau disebut juga throttle-body fuel injection (TBI), injektor dipasang sebelum saluran isap yaitu pada throttle body. Prinsip kerja SPI memberikan suplai bahan bakar melalui injektor untuk digunakan ke beberapa silinder sekaligus (multisilinder). Multipoint fuel injection posisi injektor berada di atas lubang hisap (intake port). Pada jenis MPI ini masing-masing silinder displai oleh satu injektor. Salah satu merk yang sudah menerapkan teknlogi injeksi adalah Honda dengan slogan merk PGFM-FI (Programmed Module-Fuel Injection). PGFM-FI merupakan Sistem suplai bahan bakar dengan menggunakan teknologi kontrol elektronik sehingga mampu mengatur pasokan bahan bakar dan udara secara optimum yang dibutuhkan oleh mesin pada setiap keadaan. Sensor -sensro yang ada pada sepeda motor honda adalah sensor TP (Throttle Position) : sensor bukaan posisi throtlle, sensor O2 (Oxigen sensor), CKP sensor (Crank Shaft Position sensor) dan perangkat ECM (Electronic Control Module ) sebagai muara penerima laporan dari sensor-sensor serta memberikan proses kerja pada mesin sepeda motor Honda.

SMK merupakan salah lembaga pendidikan SLTA sederajat yang mempunyai tujuan untuk mempersiapkan siswanya untuk siap menghadapi dunia kerja. Berdasarkan data yang ada masih banyak ditemui siswa SMK yang tidak bekerja setelah lulus dari SMK. Salah satu yang menjadoi kekurangan adalah kurangnya kompetensi siswa dalam menggunakan, menganalisa serta melakukan perbaikan kerusakan sepeda motor dengan menggunakan Scan Tool . khususnya jurusan teknik sepeda motor kelas XII.masih banyak ditemukan siswa yang tidak mengetahui serta paham akan alat pendeteksi kerusakan sepeda motor Scan Tool.

Kemampuan menggunakan Scan Tool bagi siswa kelas XII jurusan teknik sepeda motor sangat dibutuhkan ketika mereka bekerja di dunia industri. Dunia industri sepeda motor khusunya honda saat ini dalam aplikasi sudah menerapkan teknologi-teknologi elektronik. Sehingga untuk pendeteksian dan analisa kerusakan menggunakan alat khusus yaitu Scan Tool khusus sepeda motor honda. Sehingga siswa yang sudah bisa menggunakan, menganalisa kerusakan sepeda motor menggunakan Scan Tool sangat diminati dan mendapat perhatian lebih oleh dunia usaha dan dunia industri khusunya sepeda motor Honda. Scan Tool sebagai sebuah alat dan media sangat dibutuhkan pada saat sekarang oleh siswa SMK. Dengan menguasai alat dan media scan tool akan memudahkan siswa SMK untuk meningkatkan kompetensinya. Saputra,H.D. (2018), dalam jurnal menyatakan bahawa media yang valid, praktis dan efektif dapat meningkatkan hasil belajar siswa. Bagi siswa SMK hasil belajar dapat berupa peningkatan pengetahuan, skill dan kompetensi.

Pihak SMK sangat menyadari akan perlunya penyesuaian kompetensi-kompetensi dari lulusannya dengan kompetensi-kompetensi yang diharapakan oleh dunia usaha dan dunia industri. Kompetensi merupakan pengetahuan, keterampilan, dan kemampuan yang dikuasai oleh siswa sehingga terjadi perubahan dan peningkatan perilaku-perilaku kognitif, afektif, dan psikomotor menjadi lebih baik. Kompetensi yang harus dikuasai oleh siswa, meliputi kemampuan untuk menguasai kompetensi-kompetensi dasar yang ada pada setiap mata diklat. 
Kompetensi dapat dilihat dari prestasi atau hasil belajar yang didapatkan oleh siswa. Secara garis besar Prestasi Belajar terbagi atas tiga ranah, yaitu:

1. Ranah kognitif, berkaitan dengan Prestasi Belajar intelektual.

2. Ranah afektif, merupakan sikap.

3. Ranah psikomotor, yang berkenaan keterampilan dan kemampuan bertindak.

Hasil belajar siswa SMK berupa kompetensi dapat dipengaruhi oleh dua yaitu : faktor internal mahasiswa dan faktor eksternal siswa. Faktor internal yang bisa mempengaruhi antara lain minat, motivasi, disiplin dll. Saputra,H.D. (2018), memberikan gambaran bahwa motivasi memiliki pengaruh terhadap hasil belajar siswa memiliki. Sehingga dalam pelatihan ini siswa yang mempunyai motivasi untuk ikut pelatihan akan mempunyai hasil belajar yang tinggi pula.Beberapa kendala yang sering dihadapi SMK adalah, masih minimnya bantuan berupa Scan Tool dari pihak terkait yang dapat digunakan untuk pratikum Teknologi sepeda motor sehingga siswa kelas XII tidak dapat belajar maksimal dan optimal dalam penguasaan dan penggunaan teknologi Scan Tool. Salah satu SMK dijadikan observasi adalah SMK Karya Padang Panjang. Pada sekolah ini terdapat jurusan Teknik Sepeda Motor . Jurusan Teknik sepeda Motor hanya mempunyai satu laboratorium tempat praktek. Hal ini menjadikan pembelajaran kurang maksimal dan optimal, idealnya jurusan teknik sepeda motor memliliki laboratorium khusus untuk penggunaan, analisa dan perbaikan khusus teknologi terbaru sepeda motor Honda. Sehingga siswa-siswa SMK kelas XII dapat belajar penggunaan, analisa dan perbaikan dengan optimal dan maksimal. Kebutuhan penguasaan dan penggunaan teknologi Scan Tool sangat mutlak bagi siswa kelas XII Teknologi Sepeda Motor. Kemampuan ini menjadi salah satu syarat wajib jika ingin bergabung dengan perusahaan Honda.

\section{Solusi dan Target}

Kegiatan pengabdian kepada masyarakat yang diselenggarakan oleh UNP merupakan salah satu upaya dari pihak UNP untuk memberikan solusi kepada pihak SMK karya Padang Panjang bagi kelas XII teknik sepeda motor untuk meningkatkan kompetensi siswa tentang teknologi sepeda motor tebaru. Melalui program Pelatihan Teknologi Sepeda Motor di SMK Karya Padang panjang, dalam hal ini pesertanya sebanyak 20 orang. Pesertanya diutamakan bagi siswa kelas XII jurusan Teknik Sepeda Motor. Pelatihan dimulai dari penguasaan teori dasar teknologi konvensional, dilanjutkan dengan teknologi sepeda motor honda selanjutnya praktek penggunaan alat Scan Tool bagi siswa. Melalui kegiatan pelatihan ini diharapkan nantinya terjadi peningkatan kompetensi siswa kelas XII jurusan teknik sepeda motor dalam pendeteksian dan analisa kerusakan menggunakan alat khusus yaitu Scan Tool. Sehingga siswasiswa kelas XII jurusan teknik sepeda motor jika lulus nantinya dapat langsung bekerja.

Pada pelatihan ini diharapkan siswa mampu membaca sensor-sensor yang ada pada sepeda motor dan mampu membaca kode-kode lampu kerusakan atau MIL (Mallfunction Indicator Lamp). 
Suluah Bendang: Jurnal Ilmiah Pengabdian Kepada Masyarakat

Vol.19, No.3, 2019

Hendra Dani Saputra, Dedi Setiawan, dkk

\begin{tabular}{ll}
\hline \multicolumn{1}{c}{ Tabel 1. Kode lampu MIL sepeda motor Honda } \\
\hline 1 kedipan & \multicolumn{1}{c}{ Kode Gangguan } \\
\hline 7 Kedipan & Manifold Absolute Pressure (MAP) \\
& $\begin{array}{l}\text { Engine Oil Temperature (EOT) } \\
\text { Engine Coolant Temperature (ECT) }\end{array}$ \\
\hline 8 Kedipan & Throttle Position (TP) \\
\hline 9 Kedipan & Intake Air Temperature (IAT) \\
\hline 12 Kedipan & Injector \\
\hline 29 Kedipan & O2 Sensor \\
\hline 29 Kedipan & Idle Air Control Valve \\
\hline 33 Kedipan & (IACV) \\
\hline 52 Kedipan & Engine Control Module (ECM) \\
\hline 54 Kedipan & Crank Position Sensor (CKP) \\
\hline
\end{tabular}

Dengan adanya kode-kode lampu MIL diatas diharapkan siswa mempunyai skill/ keahlian membaca dan memberikan solusi terhadap kerusakan yang terjadi pada sepeda motor.

\section{METODE PELAKSANAAN}

\section{Tempat dan Waktu}

Kegiatan Pengabdian dilakukan kepada 20 orang siswa Program Keahlian Teknik Sepeda Motor SMK Karya Padang Panjang. Kegiatan dilaksanakan pada tanggal 14-16 September 2018 di Karya Padang Panjang.

\section{Khalayak Sasaran}

Kegiatan Pengabdian ditujukan kepada 20 orang siswa Program Keahlian Teknik Sepeda Motor SMK Karya Padang Panjang.

\section{Metode Pengabdian}

Dalam pelaksaan Pengabdian digunakan metode-metode sebagai berikut Metode ceramah dan tanya jawab

Dalam pelaksanaanya digunakan teknik penyajian informasi berupa informasi umum tentang teori sepeda motor mesin konvensional dan diteruskan dengan teori mesin sepeda motor teknologi terbaru (Injeksi). Lapisa, R., Basri. I.Y.,Arif, A., dkk.(2017) memberikan gambaran jelas bagaimana metode ceramah dan tanya jawab. [3] Kemudian diberikan beberapa kesempatan memberikan pertanyaan kepada baik dari siswa maupaun dari instruktur seputar pengetahuan teknologi sepeda motor.

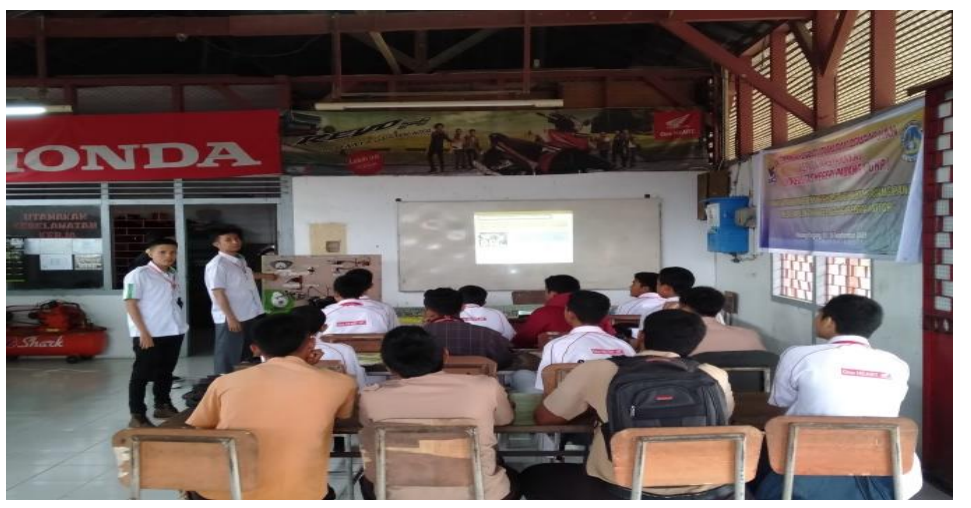

Gambar 1. Aktifitas kegiatan penyajian informasi tentang teknologi sepeda motor 


\section{Metode Demontrasi dan praktek langsung}

Instruktur mendemontrasikan kepada peserta langkah-langkah tentang teknologi sepeda motor berupa lokasi sensor-sensor, cara melakukan reset sensor dengan scan tool, kodekode lampu kerusakan sepeda motor. Kemudian dilanjutkan dengan praktek langsung cara melakukan reset terhadap sensor-sensor yang telah di cabut koneksinya dari sepeda motor Selanjutnya diberikan kesempatan kepada siswa untuk berlatih dan melakukan instruksiintruksi yang telah didemontrasikan oleh instruktur.

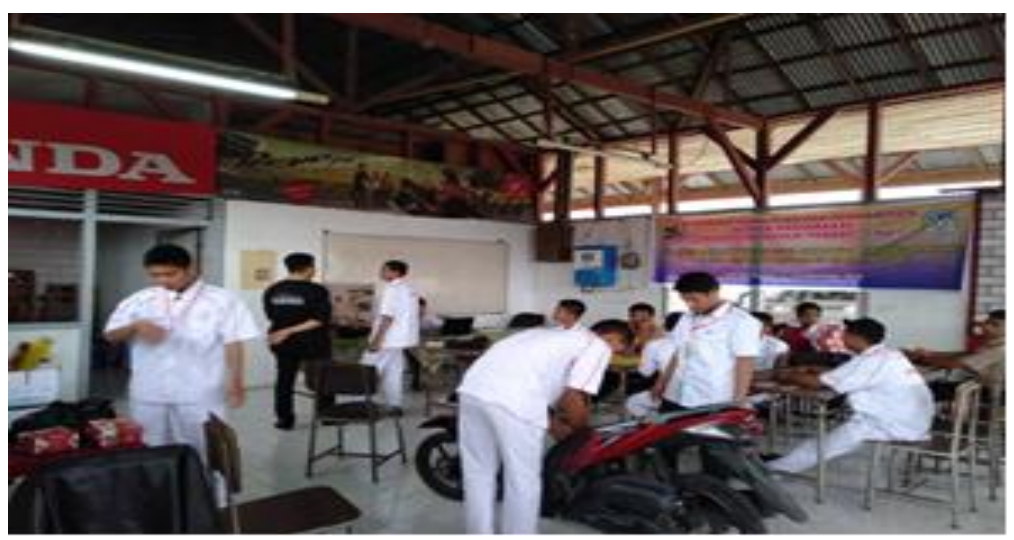

Gambar 2. Aktifitas kegiatan mendemontrasikan dan praktek langsung lokasi sensor-sensor sepeda motor

Sehingga dengan pelatihan yang dilakukan, siswa dapat memahami dan melakukan langkah-langkah pengecekan sensor dan melakukan reset (kembali ke kondisi ) awal sepeda motor dengan menggunakan scan tool.

\section{Metode Evaluasi}

\section{Evaluasi Saat Kegiatan}

\section{Kehadiran Peserta}

Peserta yang mengikuti pelatihan berjumlah 15 orang siswa. Semua peserta pelatihan dapat mengiktui semua kegiatan pelatihan . Pelatihan dipadatkan 3 hari mulai jumat-sabtu dan minggu tanggal 14-16 september 2018, dimulai pukul 08.00-18.00 WIB. Selama pelaksanaan pelatihan peserta tetap semangat mengikuti pelatihan dan penuh kedipsilinan mengikuti semua materi pelatihan .

Sikap dan Antusiasme Peserta Selama Pelatihan

Selama pelatihan berlangsung peserta sangat antusias selama mengikuti pelatihan . Hal ini dapat dilihat dari sikap peserta pelatihan yang tidak mau meninggalkan tempat pelatihan. Tingkat kedisiplinan peserta sangat tinggi yaitu selalu mematuhi jadwal yang telah ditetapkan oleh panitia.

\section{Keingintahuan Peserta}

Selama pelatihan diberikan peserta sangat serius mendengarkan materi tentang teknologi sepeda motor, tentang sensor-sensor pada sepedaa motor dan materi kode lampu kerusakan pada sepeda motor. Disamping itu peserta sangat ingin tahu dang sangat ingin mencoba melakukan bagaimana cara membaca dan melakukan reset kerusakan sensor dengan scan tool, ketika sepeda motor mengalami masalah. Peserta tidak ragu untuk bertanya jika ada hal-hal yang masih belum dipahaminya. 
Suluah Bendang: Jurnal Ilmiah Pengabdian Kepada Masyarakat

Vol.19, No.3, 2019

Hendra Dani Saputra, Dedi Setiawan, dkk

Berikut ini merupakan tahapan dan dokumentasi kegiatan pelatihan yang dilakukan:

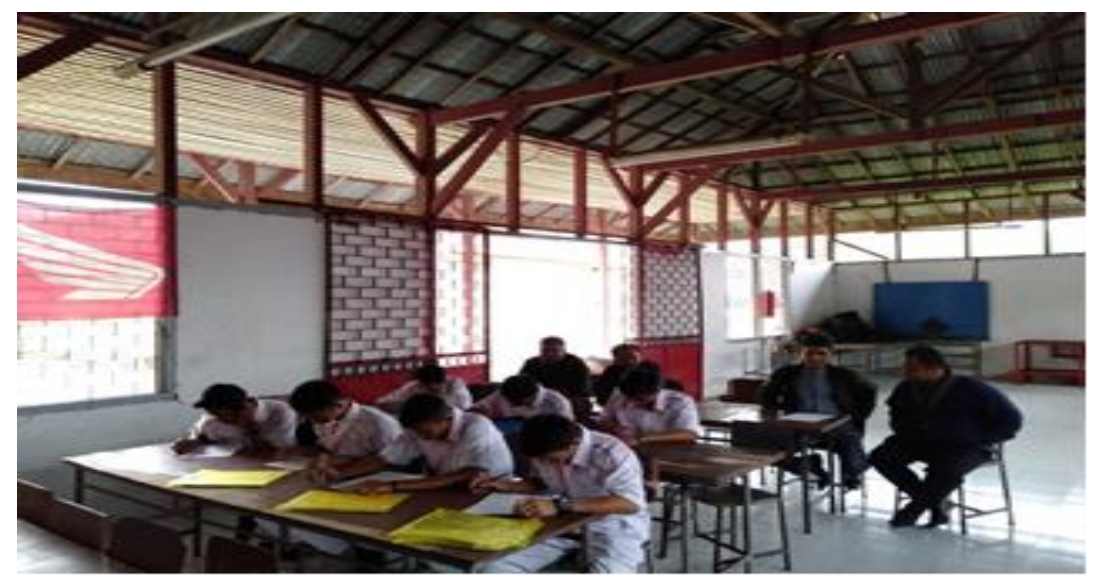

Gambar 3. Aktifitas kegiatan evaluasi awal

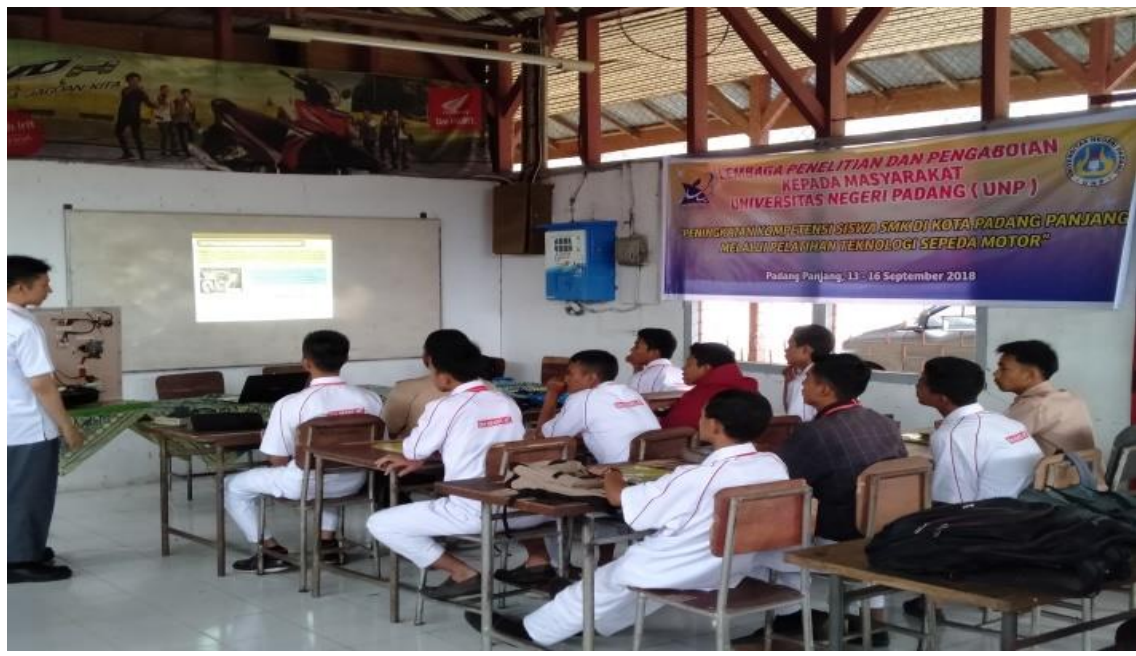

Gambar 4. Aktifitas kegiatan penyajian informasi tentang teknologi sepeda motor

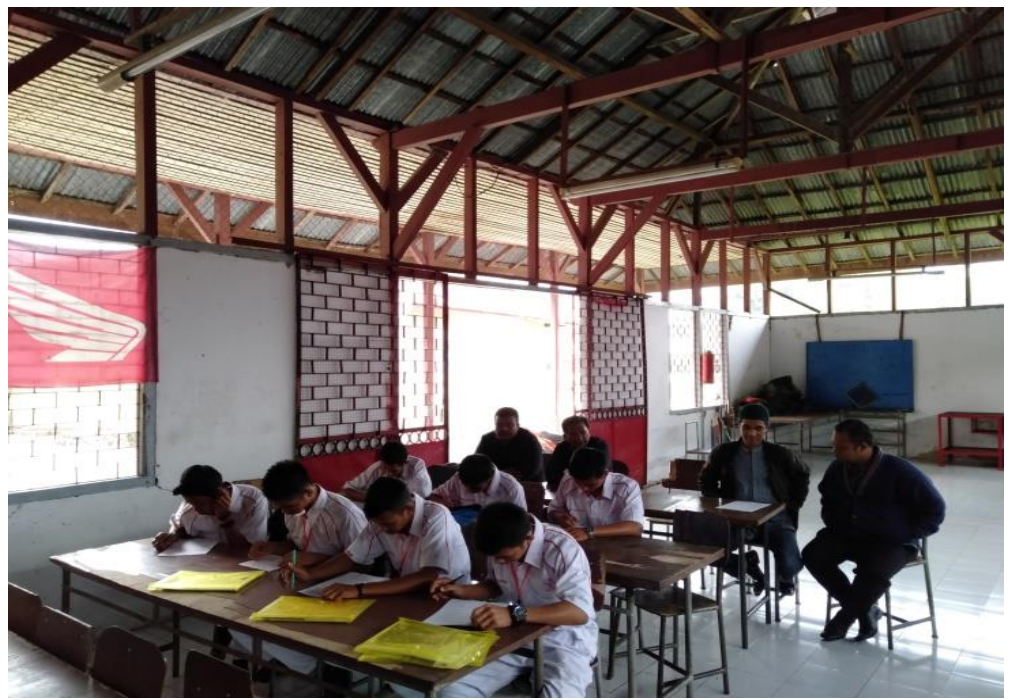

Gambar 5. Test Akhir Pelatihan 


\section{HASIL DAN PEMBAHASAN}

Hasil

Berdasarkan hasil evaluasi awal dan akhir pelatihan, maka dapat diberikan kesimpulan bahwa peserta dengan penuh semangat mengikuti pelatihan dan penuh kedipsilinan mengikuti semua materi pelatihan Tingkat kedisiplinan peserta sangat tinggi. Siswa memberikan Feed back yang sangat baik selama pelatihan sehingga

Dengan pelatihan yang dilakukan terjadi peningkatan pengetahuan dan kemampuan peserta tentang teknologi sepeda motor.hal ini dapat dilihat pada gambar grafik 6 berikut ini.

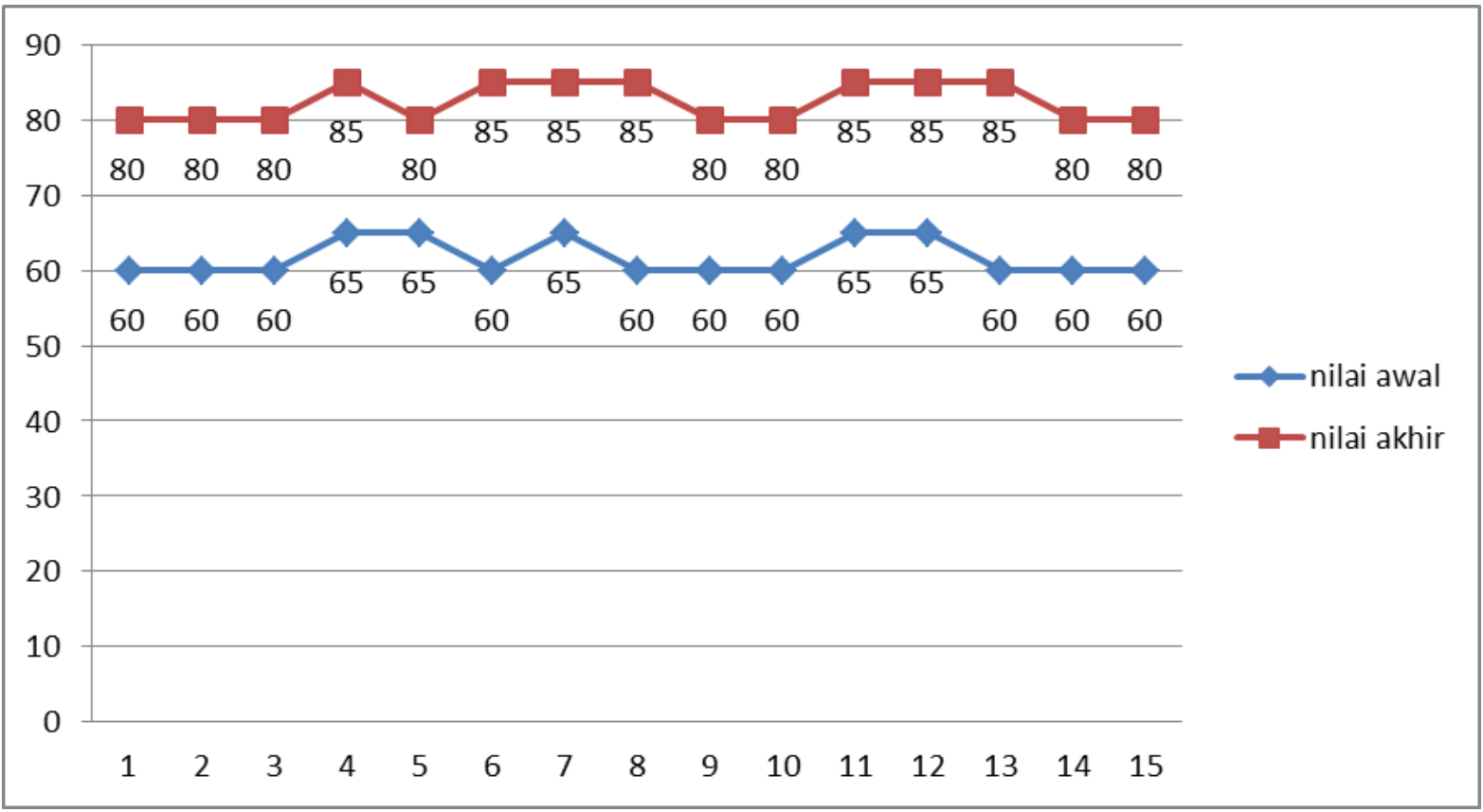

Gambar 6. Grafik peningkatan pengetahuan peserta pelatihan

Dari Gambar 6 diatas dapat disimpulkan melalui kegiatan pelatihan teknologi sepeda motor yang diberikan kepada siswa, dapat meningkatkan kompetensi, pengetahuan dan kemampuan siswa tentang teknologi sepeda motor.

Pembahasan

Kegiatan pelatihan teknologi sepeda motor telah mencapai sasaran yang sesuai dengan yang diharapkan. Hal ini dilihat dari hasil akhir nilai pengetahuan dan keterampilan yang telah diperoleh oleh peserta pelatihan. Peserta pelatihan mampu mampu memahami, membaca sensor-sensor, membaca kode-kode kerusakan dan melakukan reset dengan menggunakan scan tool. Kemampuan yang diiringi dengan rasa percaya diri yang tinggi dari peserta dapat ditunjukkan dengan antusiasnya peserta mengikuti pelatihan serta diiringi dengan peningkatan terhadap kemampuan yang telah mereka miliki. Peserta pelatihan juga berharap agar kegiatan pelatihan ini bisa diperpanjang, sehingga mereka bisa makin meningkatkan kemampuan teknologi sepeda motor yang berhubungan dengan penggunaan Scan Tool. Komunikasi antara instruktur dengan peserta pelatihan juga tidak terputus meskipun pelatihan sudah berakhir. Tetap terjalin komunikasi yang baik antara instruktur dengan peserta pelatihan. baik melalui media sosial, telepon maupun peserta datang ke kampus.

\section{KESIMPULAN}

Kegiatan pelatihan teknologi sepeda motor merupakan salah satu kegiatan pengabdian kepada masyarakat yang bertujuan untuk meningkatkan pengetahuan dan kemampuan ( 
kompetensi) peserta pelatihan (siswa) dalam memahami dan melakukan perbaikan teknologi sepeda motor dengan mengunakan scan tool. Rasa ingin tahu, disiplin dan antusiasme peserta selama pelatihan sangat tinggi sehingga hal ini memudahkan siswa untuk mendapatkan pengatahuan dan keterampilan selama mengikuti pelatihan. Sehingga dengan pelatihan yang berjenjang sesudah pelatihan ini diharpkan siswa mampu secara mandiri melakukan service sepeda motr injeksi.

\section{DAFTAR PUSTAKA}

Saputra, H. D. (2018). Pengaruh Motivasi Terhadap Hasil Belajar Siswa SMK. Invotek : Jurnal Inovasi Vokasional dan Teknologi, 25-30.

Saputra, H. D, N Nasrun, W Wakhinuddin (2018). Development of Web-Based Learning Media in Vocational Secondary School. VOLT: jurnal ilmiah Pendidikan teknik elektro, 37-41.

PT. Astra Honda Motor. 2013, PGM-FI System (Programmed Fuel Injection System, Technical Service Division-Technical Training Dept.

Lapisa, R. B. (2017 Vol 17 (2). Peningkatan Kompetensi Siswa Melalui Pelatihan Auto CAD. INVOTEK: Jurnal Inovasi Vokasional dan Teknologi, 119-126. 